\title{
Bacterial sinusitis: a striking complication report
}

Sinusitis is a mucous inflammatory process of the paranasal and nasal sinuses and is frequently associated with respiratory infections. Complications related to bacterial sinusitis are increasingly rare, which makes this case report highly relevant. The clinical case refers to a female patient of 53 years old, admitted in the hospital emergency service with inflammation signals in left hemiface and left periorbital region and with left nasal discharge with pus secretion and malodorous (Figure 1). When the patient arrived, it was also observed necrosis in third, fourth and fifth toes with the same time of evolution (Figure 2). Moreover, the patient presented hypotension (maximum systolic blood pressure of $60 \mathrm{mmHg}$ ), tachycardia (frequencies above $100 \mathrm{bpm}$ ) and auricular temperature of $39.5^{\circ} \mathrm{C}$. Blood analysis indicated leucocytes at $4.2 \times 10^{3} / \mathrm{uL}, \mathrm{C}$ reactive protein of $6.1 \mathrm{mg} / \mathrm{dL}$ and lactates of $0.6 \mathrm{mmol} / \mathrm{L}$, with no other significant changes. A support therapeutic strategy was started as well as antibiotics with meropenem $(1 \mathrm{~g}, 8-8$ $\mathrm{h}$, intravenous) and vancomycin (1 g, 12-12 h, intravenous), and a surgical drainage of the face sinuses was scheduled. The haemocultures were positive for Staphylococcus hominis multiresistant (only sensitive to vancomycin and carbapenems) and the nasal exudate culture was revealed polymicrobial, incluinding S. hominis. The Head Computed Tomography showed total fill of left maxillary, sphenoid and ethmoid sinuses, with extension to the facial and periorbital cellular subcutaneous tissue. The Computed Tomography Angiography of the lower members did not show alterations and it was assumed septic embolization. It was performed a transthoracic echocardiogram that excluded bacterial endocarditis. Although initially the patient was deteriorated, she had a progressive improvement resulting in the resolution of the infection.

This clinical case is particularly interesting as complications related to bacterial sinusitis are increasingly rare. The case can be severe, leading to a septic embolization with gangrene of several toes tretated with conservative measures.

Acknowledgment: Dr. Amílcar Silva' ${ }^{1}$ Prof. Dr. Adriano Rodrigues ${ }^{1}$ ${ }^{1}$ Serviço de Medicina Interna B, Hospital Geral do Centro Hospitalar e Universitário de Coimbra

\section{BIBLIOGRAPHY}

1. Rosenfeld RM, Priccirillo JF, Chandrasekhar SS, Brook I, Ashok K, Kramper M, et al. Clinical practice guideline: adult sinusitis. Otolaryngol Head Neck Surg 2015; vol. 152:s1-S39.

2. Lee $S$ and Yen MT. Management of preseptal and orbital cellulitis. Saudi J Ophthalmol 2011; 25:21-9.

3. Amer M and Amer A. Rarely seen infections. Clin Dermatol 2014; 32:744-51.
Figure 1. Oedema and blush in left hemiface and left periorbital region

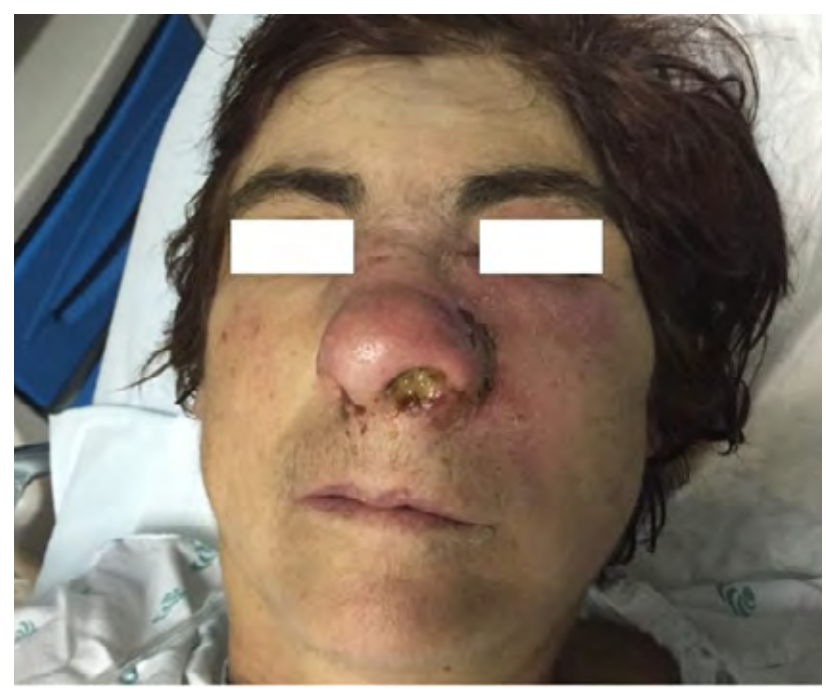

Figure 2. Necrosis in left toes

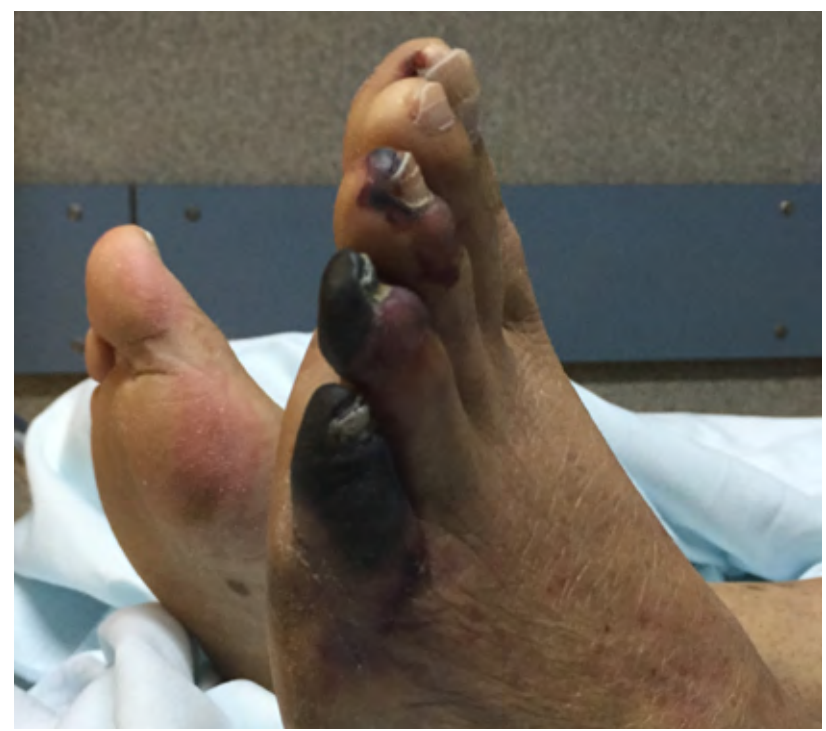

DIAGNOSIS

Severe complication of a sinusitis: septic embolization with gangrene of several toes

\section{Joana Cascais Costa ${ }^{1}$, Catarina Lucas ${ }^{1}$}

${ }^{1}$ Serviço de Medicina Interna B, Hospital Geral do Centro Hospitalar e Universitário de Coimbra, Quinta dos Vales, 3041-801 S. Martinho do Bispo, Coimbra 